\title{
Recent advances in stem cell therapeutics and tissue engineering strategies
}

\author{
Seong Gyu Kwon ${ }^{1}$, Yang Woo Kwon ${ }^{1}$, Tae Wook Lee ${ }^{1}$, Gyu Tae Park ${ }^{1}$ and Jae Ho Kim ${ }^{1,2^{*}}$ (D
}

\begin{abstract}
Background: Tissue regeneration includes delivering specific types of cells or cell products to injured tissues or organs for restoration of tissue and organ function. Stem cell therapy has drawn considerable attention since transplantation of stem cells can overcome the limitations of autologous transplantation of patient's tissues; however, it is not perfect for treating diseases. To overcome the hurdles associated with stem cell therapy, tissue engineering techniques have been developed. Development of stem cell technology in combination with tissue engineering has opened new ways of producing engineered tissue substitutes. Several studies have shown that this combination of tissue engineering and stem cell technologies enhances cell viability, differentiation, and therapeutic efficacy of transplanted stem cells.

Main body: Stem cells that can be used for tissue regeneration include mesenchymal stem cells, embryonic stem cells, and induced pluripotent stem cells. Transplantation of stem cells alone into injured tissues exhibited low therapeutic efficacy due to poor viability and diminished regenerative activity of transplanted cells. In this review, we will discuss the progress of biomedical engineering, including scaffolds, biomaterials, and tissue engineering techniques to overcome the low therapeutic efficacy of stem cells and to treat human diseases.

Conclusion: The combination of stem cell and tissue engineering techniques overcomes the limitations of stem cells in therapy of human diseases, and presents a new path toward regeneration of injured tissues.
\end{abstract}

Keywords: Tissue injury, Nanoparticle, Stem cells, Biomaterials, Tissue engineering

\section{Background}

The growing tendency of increased life expectancy as well as increased incidence of age-related degenerative diseases and tissue damage requires the use of allogenic or autologous grafts for tissue repair. Although transplantation of tissues or cells is innovative and has been applied to a lot of treatments, its application in clinical settings is still limited [1]. Accumulating evidence suggests that stem cells can accelerate the tissue regeneration through various mechanisms. To date, a variety of stem cells, including mesenchymal, embryonic, and induced pluripotent stem cells, have been reported to promote regeneration of damaged tissues [2]. Although stem cell therapy provides a new paradigm in tissue regeneration, they have limitation in clinical application due to poor survival and

\footnotetext{
* Correspondence: jhkimst@pusan.ac.kr

'Department of Physiology, Pusan National University School of Medicine, Yangsan 50612, Gyeongsangnam-do, Republic of Korea

${ }^{2}$ Research Institute of Convergence Biomedical Science and Technology, Pusan National University Yangsan Hospital, Yangsan 50612, Republic of Korea
}

(C) The Author(s). 2018 Open Access This article is distributed under the terms of the Creative Commons Attribution 4.0 International License (http://creativecommons.org/licenses/by/4.0/), which permits unrestricted use, distribution, and

reproduction in any medium, provided you give appropriate credit to the original author(s) and the source, provide a link to the Creative Commons license, and indicate if changes were made. The Creative Commons Public Domain Dedication waiver (http://creativecommons.org/publicdomain/zero/1.0/) applies to the data made available in this article, unless otherwise stated. overcome these limitations, tissue engineering technology has been used to improve the viability and proliferative capacity of stem cells. Tissue engineering is the use of a combination of cells, biomaterials, biochemical and physicochemical factors, and engineering technologies to improve or replace biological tissues [4]. In this paper, we will review the types of stem cells, their use in various tissues, and tissue regeneration through stem cell engineering. In addition, there are many other kinds of stem cells that can be used for tissue regeneration; however, in this review, we focus on the above-mentioned stem cells for tissue regeneration.

\section{Types of stem cells for tissue regeneration}

Mesenchymal stem cells (MSCs) can be isolated from various tissues, such as adipose tissue, tonsil, and bone marrow. MSCs show plastic adherent properties under normal culture conditions and have a fibroblast-like morphology. They express specific cell surface markers including CD73, CD90, and CD105. MSCs have the 
potential for self-renewal and differentiation potential into mesodermal lineages, including adipocytes, muscles, chondrocytes, and osteoblasts [2]. In addition to the differentiation potential, increasing body of evidence suggests that MSCs possess immune modulatory function and pro-angiogenic activity which are beneficial for tissue regeneration [5]. MSCs interfere with dendritic cell and T-cell function and generate a local immunosuppressive environment by secreting various immune-modulatory cytokines [6]. Moreover, MSCs promote angiogenesis by secreting pro-angiogenic factors [7]. Therefore, MSCbased clinical trials have been conducted worldwide for various human diseases, including cardiovascular, bone and cartilage, neuronal, and inflammatory diseases [8]. Several MSC-based cell therapeutics are commercially available [9], although their therapeutic efficacy is still in debate.

Embryonic stem cells (ESCs) are pluripotent stem cells derived from the inner cell mass of blastocysts, and they can differentiate to specific cell types by controlling culture conditions [10]. Recently, clinical trials were initiated to test the safety and potential efficacy of human ESCs in several diseases, including spinal cord injury, macular degeneration, diabetes and heart diseases. In 2010, Geron Corporation transplanted hESC-derived oligodendrocyte precursors, GRNOPC1, into five patients with spinal cord injury, and the clinical trial data suggest long-term safety of the therapy as well as reduced spinal cord cavitation in four of the five patients [11]. In addition, Advanced Cell Technology (MA, USA) tested human ESC-derived retinal pigment epithelium for age-related macular degeneration and Stargardt disease, a juvenile form of macular degeneration, and the clinical trial data have shown positive safety data with no tumorigenicity and improved clinical data in some patients [12]. Although ESCs have prominent advantages such as pluripotency and self-renewal potential, there are several obstacles hindering the clinical application of ESC-based cell therapeutics [13]. Because ESCs are derived from an embryo, they are allogenic cells to the patient and thus can be subjected to immune rejection. [14]. Secondly, it is difficult to induce differentiation into a desired cell type with $100 \%$ efficiency, thus a small fraction of undifferentiated cells might remain and form teratomas. Moreover, there are ethical issues because human ESCs are derived from human embryo, which has delayed clinical application of ESCs.

These ESC-associated issues were alleviated by the work of Yamanaka and colleagues on somatic cell reprogramming [15]. They demonstrated that somatic cells could be reprogrammed to a primordial stem cell state by introducing four pluripotency-inducing transcription factors. Since induced pluripotent stem cells (iPSCs) could be reprogrammed from adult somatic cells, they are free from ethical concerns [16]. Although iPSCs do not negate the risk of generating tumors, transplantation of autologous iPSC-derived cell therapeutics could help solve the immunological problem associated with transplantation of ESC-derived cells [17]. Japan's RIKEN Institute successfully transplanted the world's first iPSC-derived therapy into age-related macular degeneration patients [18]. However, there is a risk of neoplastic development from cells differentiated from iPSCs, because reprogramming factors are associated with the development of tumors [19].

\section{Development of stem cell-activating growth factors and peptides}

Stem cells can differentiate into different kinds of cell types in response to specific ligands or growth factors (Fig. 1) [20]. Direct transplantation of stem cells into injured tissues was found to be effective in animal models; however, the possibility of inducing local ischemia or thrombosis has been raised [21]. Moreover, stem cell-based cell therapy has been hampered by poor survival of transplanted stem cells in vivo. Therefore, there is a need to develop stem cell-activating factors that enhance the survival, paracrine effects, and therapeutic efficacy of transplanted stem cells. In particular, BMPs have been shown to exert novel effects on cartilage and bone regeneration in several animal experiments. It has been reported that bone morphogenetic proteins (BMPs) and bone-forming peptide- 3 stimulated differentiation of MSCs to osteoblasts [22, 23]. Among the various types of BMPs, both BMP2 and BMP7 have been shown to play important roles in bone and cartilage regeneration $[24,25]$.

Not only growth factors but also extracellular matrix proteins have been shown to promote the regenerative potentials of stem cells. Co-transplantation of MSCs along with collagen matrix or fibrin to the injured tissue site is now widely used clinically [26]. Periostin, an extracellular matrix protein that is expressed in the periosteum and periodontal ligaments, has been identified as a secreted protein of MSCs. Recombinant periostin protein stimulates proliferation, adhesion, and survival of MSCs in vitro, and co-implantation of MSCs and recombinant periostin protein significantly accelerates bone regeneration by increasing angiogenesis in a calvarial defect animal model [27]. Moreover, recombinant periostin and its fasciclin I domain promote therapeutic angiogenesis in a murine model of chronic limb ischemia [28]. Periostin stimulates angiogenesis and chemotaxis of endothelial colony forming cells through a mechanism involving $\beta 3$ and $\beta 5$ integrins. Recently, a short peptide sequence (amino acids 142-151), which is responsible for periostin-mediated angiogenesis, has been identified by serial deletion mapping of the first 


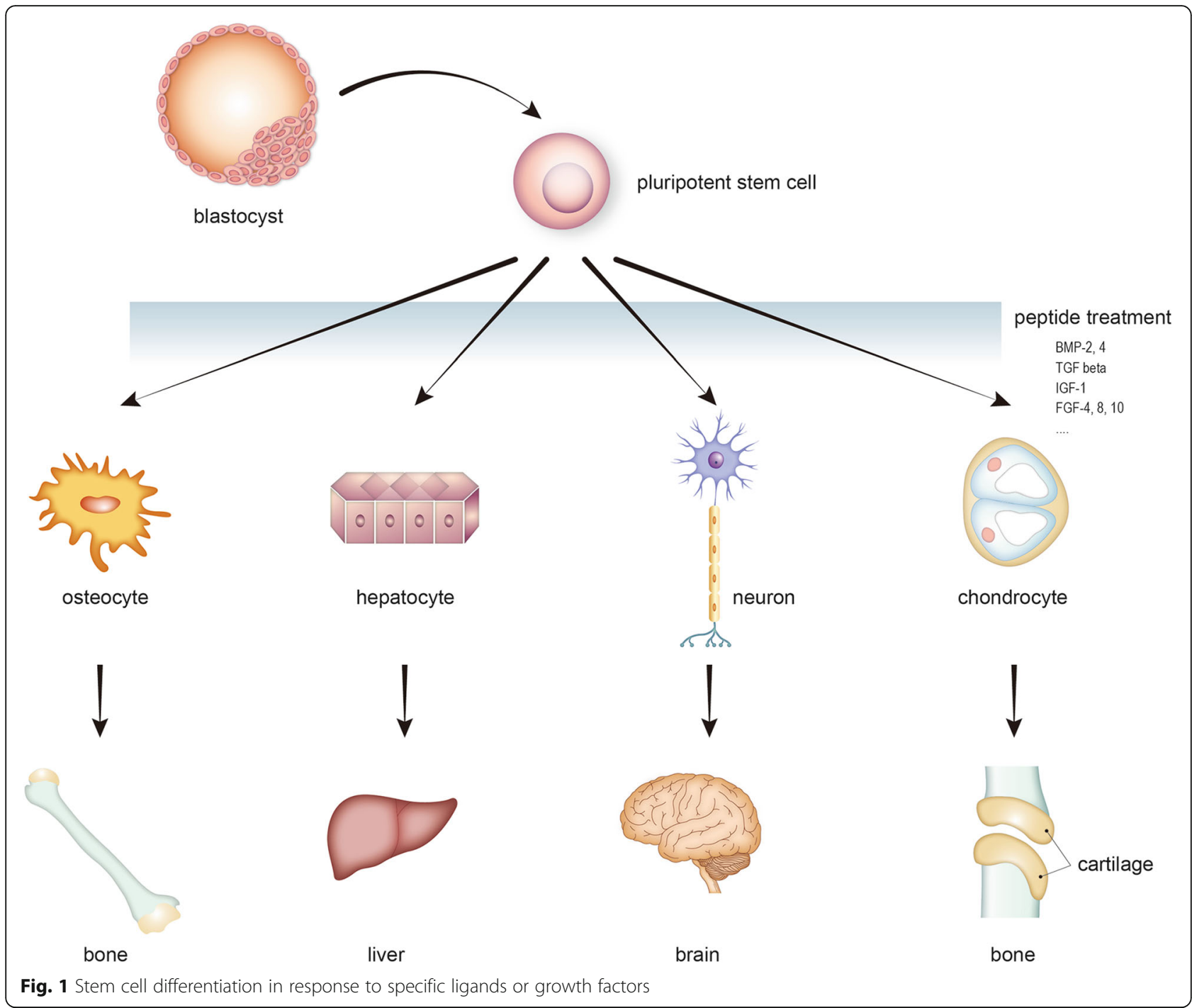

fasciclin I domain [29]. These results suggest that periostin can be applied for cell therapy by stimulating the pro-angiogenic and tissue regenerative potentials of MSCs.

In addition, it has been reported that co-transplantation of $\mathrm{N}$-acetylated proline-glycine-proline, a peptide produced by the degradation of collagen, accelerates repair of dermal wounds by stimulating migration and engraftment of transplanted endothelial colony forming cells [30]. These results demonstrate that pro-angiogenic peptides, including periostin and $\mathrm{N}$-acetylated proline-glycine-proline, promote regenerative potentials of transplanted stem cells by accelerating angiogenesis.

\section{Stem cells engineered with nanomaterials}

While growth factors and cytokines can affect the biological functions of stem cells from "outside", there are several ways to manipulate them from "inside", as an approach on a more fundamental level. Gene therapy using viral expression systems is a well-known traditional method for manipulating the biological functions of stem cells from "inside". However, viral expression systems have been reported to induce immune and inflammatory reactions in host tissues, and genetic mutations in host DNA can occur [31]. Therefore, development of highly efficient non-viral expression system is important for stem cell research. For instance, reprogramming or direct conversion of somatic cells by using non-viral gene expression system have great potential for clinical application of the reprogramming cells. Replacing viruses with alternative extracellular chemicals or delivery systems can reduce tumor formation. Non-viral methods include electroporation of cell membrane or delivery of genes in a form complexed with liposome or cationic polymers. Several types of nanoparticles have been developed for non-viral delivery of reprogramming factors into cells. These nanoparticles are composed of mesoporous silica, calcium phosphate, chitosan, cationic 
polymers, and magnetic nanoparticles [32]. Recently, graphene oxide-polyethylenimine complexes have been reported to be an efficient and safe system for mRNA delivery for direct reprogramming of somatic cells to induced neurons [33]. Therefore, improvement of gene delivery efficiency using nanoparticles will be highly useful for direct conversion or reprogramming of somatic cells.

\section{Biomaterials enhancing the therapeutic efficacy of stem cells}

Tissues are composed of two components: cells and their surrounding extracellular matrix (ECM), which is known to play an important role in cell proliferation and differentiation. The main function of the ECM is maintaining cell growth and supplying essential components to cells [34]. ECM has been reported to create a framework for cell growth and to efficiently provide the nutrients or growth factors needed for cells [35]. It is difficult to naturally repair a large-size tissue defect by supplying cells to the injured sites, since not only the cells, but also the ECM are lost. Therefore, to promote tissue regeneration, it is necessary to make an artificial ECM environment for transplanted cells, and biomaterials are useful substitutes for ECM, and are also useful in cell therapy. The biomaterial scaffold should be porous for infiltration by cells into scaffolds, and for the supply of oxygen and nutrients to cells. In addition, the scaffold should be biodegradable for proper replacement of damaged tissues with the transplanted cells [36].

In terms of biomaterials, a variety of synthetic and natural materials have been developed. In particular, biodegradable polymers, such as collagen, gelatin, fibrin, hyaluronic acid, and poly(lactic-co-glycolic acid), are highly useful for tissue engineering [37]. The combination of these scaffolds and stem cells was used for skin wound healing [38]. The osteogenic efficiency of MSCs was confirmed in duck's foot-derived collagen/hydroxyapatite scaffolds [39]. In addition, the increase of chondrogenic differentiation of MSCs in 3D alginate hydrogels was experimentally confirmed [40]. Neural stem cells have been used for treatment of neurodegenerative disease or stroke in pre-clinical and clinical studies; however, differentiation of neural stem cells to functional neurons, reconnection with host neural cells, and correct transmission of nerve signals are still obstacles to overcome [41]. Therefore, to enhance the survival and differentiation potentials of transplanted stem cells, it is necessary to combine biomaterials with growth factors, cytokines, and cell adhesive substances (Fig. 2).

\section{D bioprinting for tissue engineering}

Biomaterial scaffolds can be used as structural components for different parts of tissues, such as blood vessels, skin, and corneal tissues [42, 43]. Making 3D scaffolds and culturing stem cells on them improves the regenerative activity of stem cells for damaged bone and cartilage. Most tissues are composed of different cell types and multi-layered structures. Therefore, multi-layered 3D scaffolds are needed for construction of engineered tissues using stem cells. Currently, 3D bioprinting has drawn attention in the field of biotechnology for producing multi-layered structure. Since the first technology for 3D bioprinting cells had been reported, there have been great advances in 3D bioprinting-based tissue engineering [44]. Using 3D bioprinting, various cell types can be positioned in specific locations in multi-layered structures for constructing different tissues or organs (Fig. 3) [45]. Bioprinting technologies include inkjet [46] and laser deposition [47].

In using inkjet printer technology, however, since the cells are printed in the same manner as a commercial printer, various problems arise. For example, in order to print stem cells through an inkjet printer, the material that is added to the cells must be in a liquid form and, subsequently, have a 3D structure after injection [48]. However, employing crosslinking agents to form 3D structures can impair cellular viability [49]. Despite these drawbacks, remarkable advances have been made due to the advantage of 3D printing cells being possible with slight modifications to commercial inkjet printers on the market [50-54]. Just as laser printers have become popular, laser printers for 3D bioprinting have also been developed. Unlike inkjet printers, laser printers do not

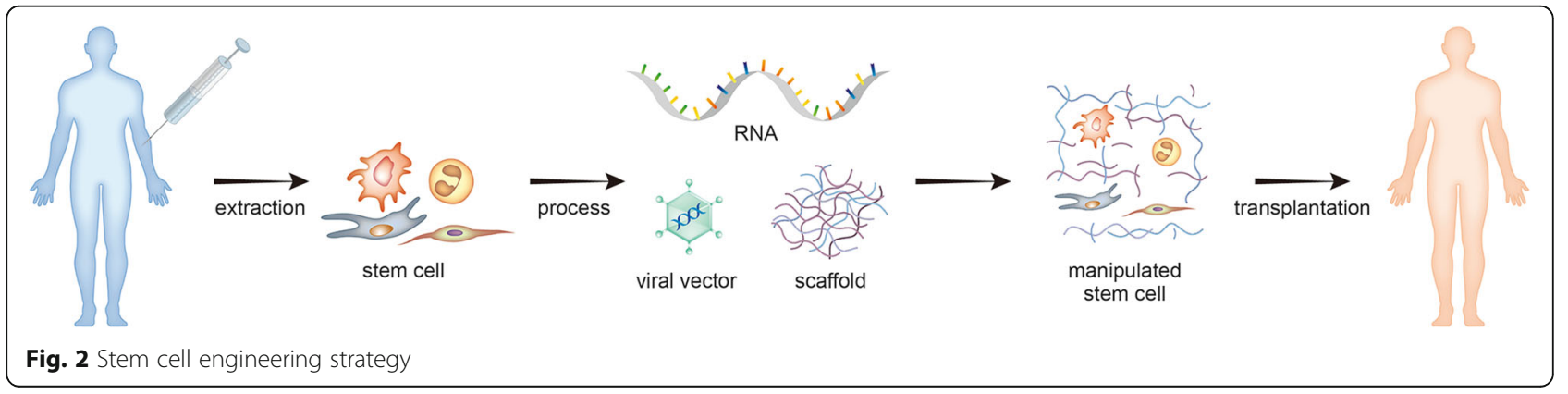




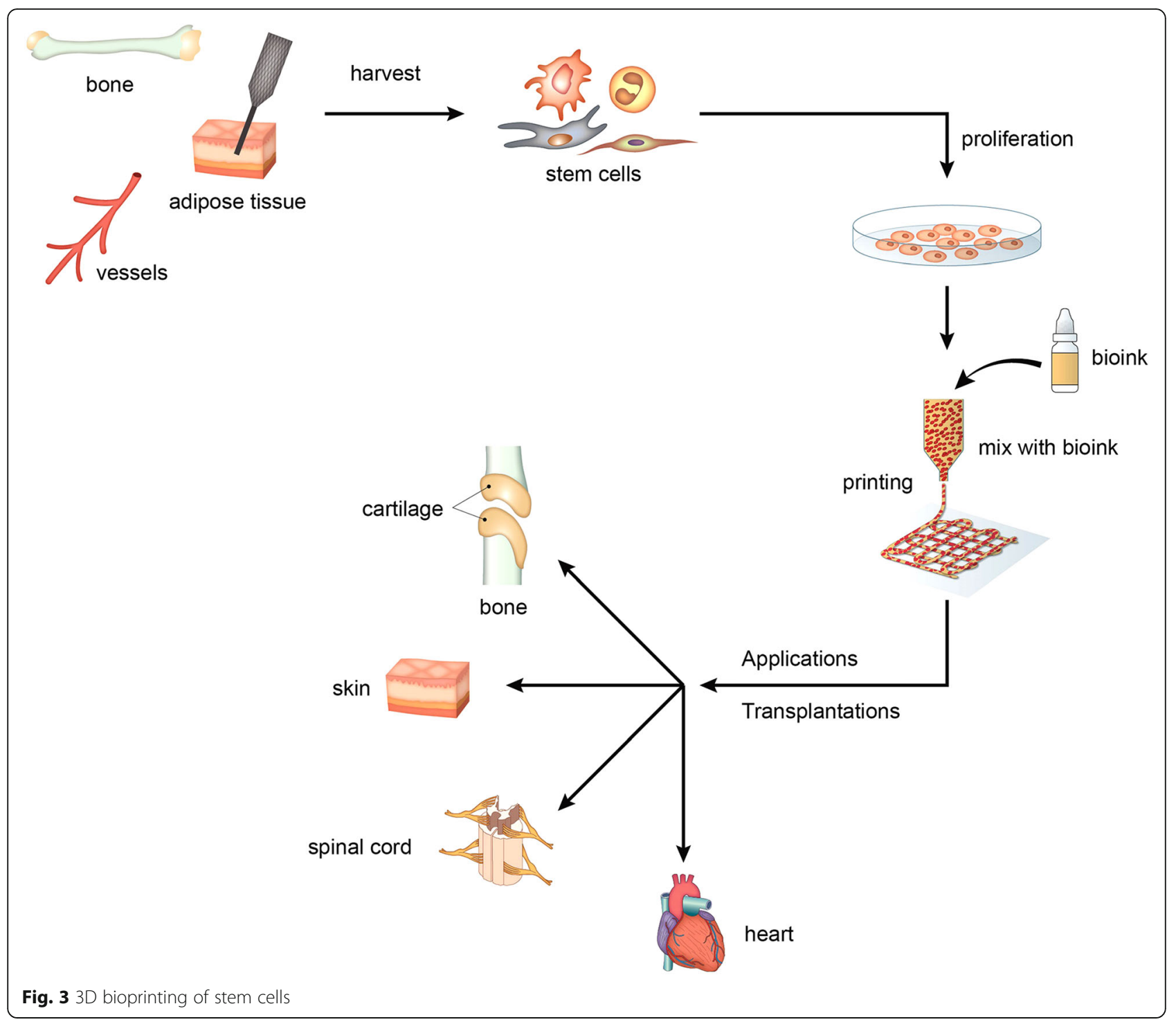

apply physical stresses and do not require additives to maintain a liquid form. The viability of cells is higher than $95 \%$ after being printed, and apoptosis and cell proliferation are not affected [55].

For 3D bioprinting, bioinks are needed for printing of stem cells into 3D structures, and hydrogels are widely used as bioinks. Each bioink has its own characteristics and is used for specific purposes [56]. Natural bioinks include alginate, gelatin, collagen I, and fibrin; synthetic bioinks include polyethylene glycol and pluronic gels [57]. These materials have chemical and physical properties appropriate for bioink, and they serve as scaffolds, similar to those of the ECM [58]. In order to mimic the ECM in vivo, de-cellularized extracellular matrix (dECM) scaffold has been developed. $\mathrm{dECM}$ is obtained by processing original tissues with chemicals, or using enzymatic methods to remove cellular components [59].
Therefore, AECM is highly useful for 3D bioprinting of stem cells, or their differentiated progeny cells.

In the regeneration of thick tissues, not only the regeneration of the tissue itself, but also the regeneration of blood vessels plays an important role in maintaining the viability of the tissue. Artificial blood vessels applied to the human body need to have various characteristics, such as elasticity, permeability, and biocompatibility comparable to the original vessels [60]. To control blood vessel fabrication, the printer should have sufficient resolution, and bioinks should not deform under the printing conditions [61]. In one study, treatment with angiogenin, a stimulator of angiogenesis, in a fibrin/bone powder scaffold enhanced angiogenesis and bone formation, compared to a control group [62]. Therefore, it is possible to add pro-angiogenic factors during $3 \mathrm{D}$ bioprinting to facilitate blood vessel formation in the $3 \mathrm{D}$ printed tissues. 


\section{Application of 3D bioprinting technology for tissue regeneration}

Recently, application of digital light processing stereolithography $3 \mathrm{D}$ printing technology for production of biodegradable polymeric vascular grafts has been reported [63]. Vascular grafts formed by 3D printing of human umbilical vein cells with poly propylene fumarate were applied for surgical grafting in patients with cardiovascular defects, suggesting that $3 \mathrm{D}$ bioprinting is highly useful for production of patient-specific vascular grafts [63]. In addition, 3D printing is also used for bone regeneration. Printed calcium phosphate scaffold have been widely used for bone regeneration [64]. Transplantation of calcium phosphate scaffold has proved effective in multiple animal studies [65]. Methods for increasing the osteogenicity of stem cells by applying polydopamine have also been developed [66]. In addition, 3D printing can be applied for cartilage regeneration. In one study, nanofibrillated cellulose plus alginate were used as scaffolds for making ears formed with a $3 \mathrm{D}$ printer, and the survival rate of chondrocytes in the scaffolds after transplantation was 73 to $86 \%$ [67]. In the case of bone and cartilage tissues, the size and shape of defects that occur in individual patients can be varied, therefore, 3D bioprinting technology may be highly useful for repair of damaged skeletal tissues [68].

Skin is the largest organ of the body, protecting the internal organs from external environments, retaining fluid, and acting as a sensory organ [69]. Thus, regeneration of skin wounds is important for not only cosmetic purposes but also restoration of physiologic function. In a clinical trial of treatment of burns, ulcers and other non-healing chronic wounds, stem cells have been proven to be an effective therapy for most patients [70]. In the case of burns or other large skin wounds, a method of transplanting through artificial skin fabricated out of polymers or human skin is widely used nowadays [71]. Although artificial skin substitutes for wound healing are commercially available, they have disadvantages such as a lack of viability, difficulty in reforming shape, and high costs [72]. It has been reported that skin-derived dECM bioinks can used to compensate for the rapid degradation and high contraction trends of traditional bioinks using conventional collagen. A printed mixture of adipose tissue-derived MSCs and endothelial progenitor cells with the skin-derived $\mathrm{dECM}$ for production of pre-vascularized skin grafts effectively accelerates cutaneous wound healing in animal models [73].

\section{Conclusions}

Most therapies or treatments eventually aim to enhance tissue regeneration, and stem cell engineering has opened a new path to regenerative medicine. In this paper, we reviewed the current status of stem cell technologies, biomedical engineering, and nanotechnology for tissue regeneration. Biomedical engineering and nanotechnology will be helpful for overcoming the shortcomings of stem cell therapeutics by supporting stem cells to grow to an appropriate concentration, offering homogeneity, and resulting in proliferation at the desired location. However, biomaterials may cause toxicity when applied to the human body; hence, several methods have been developed to increase the biocompatibility of biomaterials. Tissue engineering can be applied for construction of various tissues, such as blood vessels, nervous tissue, skin, and bone. For stem cell engineering, several techniques should be developed involving new materials, new structures, and novel surface modifications of biomaterials; in addition, a deeper understanding of the interactions between cells and biomaterials will be needed.

\section{Abbreviations \\ BMPs: Bone morphogenic proteins; dECM: De-cellularized extracellular matrix;} ECM: Extracellular matrix; MSCs: Mesenchymal stem cells

\section{Acknowledgements}

Not applicable.

Funding

This work was supported by a two year grant from Pusan National University.

Availability of data and materials

Not applicable.

Authors' contributions

The manuscript was written by contributions of all authors. All authors have given approval to the final manuscript.

Ethics approval and consent to participate

Not applicable.

Consent for publication

Not applicable.

\section{Competing interests}

The author declares that they have no competing interests.

\section{Publisher's Note}

Springer Nature remains neutral with regard to jurisdictional claims in published maps and institutional affiliations.

Received: 31 October 2018 Accepted: 7 December 2018

Published online: 19 December 2018

\footnotetext{
References

1. O'Brien FJ. Biomaterials \& scaffolds for tissue engineering. Mater Today. 2011;14(3):88-95.

2. Tong Z, Solanki A, Hamilos A, Levy O, Wen K, Yin X, et al. Application of biomaterials to advance induced pluripotent stem cell research and therapy. EMBO J. 2015;34(8):987-1008.

3. Madl CM, Heilshorn SC, Blau HM. Bioengineering strategies to accelerate stem cell therapeutics. Nature. 2018;557(7705):335-42.

4. Lee EJ, Kasper FK, Mikos AG. Biomaterials for tissue engineering. Ann Biomed Eng. 2014:42(2):323-37.

5. Murphy MB, Moncivais K, Caplan Al. Mesenchymal stem cells: environmentally responsive therapeutics for regenerative medicine. Exp Mol Med. 2013;45:e54

6. Dimarino AM, Caplan Al, Bonfield TL. Mesenchymal stem cells in tissue repair. Front Immunol. 2013;4:201.
} 
7. Fu Y, Karbaat L, Wu L, Leijten J, Both SK, Karperien M. Trophic effects of mesenchymal stem cells in tissue regeneration. Tissue Eng B Rev. 2017;23(6):515-28.

8. Squillaro T, Peluso G, Galderisi U. Clinical trials with mesenchymal stem cells: an update. Cell Transplant. 2016;25(5):829-48.

9. Jossen V, van den Bos C, Eibl R, Eibl D. Manufacturing human mesenchymal stem cells at clinical scale: process and regulatory challenges. Appl Microbiol Biotechnol. 2018;102(9):3981-94.

10. Vazin T, Freed WJ. Human embryonic stem cells: derivation, culture, and differentiation: a review. Restor Neurol Neurosci. 2010;28(4):589-603.

11. Watson RA, Tsakok MT, Yeung TM. Oligodendrocyte progenitor cells: a missed opportunity. J Neurotrauma. 2012;29(16):2593-4.

12. Song WK, Park KM, Kim HJ, Lee JH, Choi J, Chong SY, et al. Treatment of macular degeneration using embryonic stem cell-derived retinal pigment epithelium: preliminary results in Asian patients. Stem cell reports. 2015;4(5): 860-72.

13. Rong Z, Wang M, Hu Z, Stradner M, Zhu S, Kong H, et al. An effective approach to prevent immune rejection of human ESC-derived allografts. Cell Stem Cell. 2014;14(1):121-30.

14. Boyd AS, Rodrigues NP, Lui KO, Fu X, Xu Y. Concise review: immune recognition of induced pluripotent stem cells. Stem Cells. 2012;30(5):797-803.

15. Takahashi K, Yamanaka S. Induction of pluripotent stem cells from mouse embryonic and adult fibroblast cultures by defined factors. Cell. 2006; 126(4):663-76

16. Hu MS, Leavitt T, Malhotra S, Duscher D, Pollhammer MS, Walmsley GG, et al. Stem cell-based therapeutics to improve wound healing. Plast Surg Int 2015;2015:383581

17. Li Y-C, Zhu K, Young T-H. Induced pluripotent stem cells, form in vitro tissue engineering to in vivo allogeneic transplantation. Journal of thoracic disease. 2017;9(3):455-9.

18. Mandai M, Watanabe A, Kurimoto $Y$, Hirami $Y$, Morinaga C, Daimon T, et al. Autologous induced stem-cell-derived retinal cells for macular degeneration. N Engl J Med. 2017;376(11):1038-46.

19. Medvedev SP, Shevchenko Al, Zakian SM. Induced pluripotent stem cells: problems and advantages when applying them in regenerative medicine. Acta Nat. 2010;2(2):18-28.

20. Czyz J, Wobus A. Embryonic stem cell differentiation: the role of extracellular factors. Differentiation; research in biological diversity. 2001; 68(4-5):167-74.

21. Qin Y, Guan J, Zhang C. Mesenchymal stem cells: mechanisms and role in bone regeneration. Postgrad Med J. 2014;90(1069):643-7.

22. Beederman M, Lamplot JD, Nan G, Wang J, Liu X, Yin L, et al. BMP signaling in mesenchymal stem cell differentiation and bone formation. J Biomed Sci Eng. 2013;6(8A):32-52.

23. Lee JS, Kim ME, Seon JK, Kang JY, Yoon TR, Park Y-D, et al. Bone-forming peptide-3 induces osteogenic differentiation of bone marrow stromal cells via regulation of the ERK1/2 and Smad1/5/8 pathways. Stem Cell Res. 2018; 26:28-35.

24. Chang SC, Chung HY, Tai CL, Chen PK, Lin TM, Jeng LB. Repair of large cranial defects by hBMP-2 expressing bone marrow stromal cells: comparison between alginate and collagen type I systems. J Biomed Mater Res A. 2010;94(2):433-41.

25. Burastero G, Scarfi S, Ferraris C, Fresia C, Sessarego N, Fruscione F, et al. The association of human mesenchymal stem cells with BMP-7 improves bone regeneration of critical-size segmental bone defects in athymic rats. Bone. 2010;47(1):117-26.

26. Hanson SE, Bentz ML, Hematti P. Mesenchymal stem cell therapy for nonhealing cutaneous wounds. Plast Reconstr Surg. 2010;125(2):510-6.

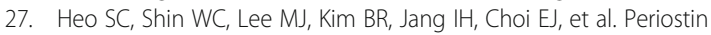
accelerates bone healing mediated by human mesenchymal stem cellembedded hydroxyapatite/tricalcium phosphate scaffold. PLoS One. 2015; 10(3):e0116698.

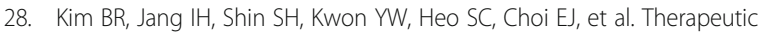
angiogenesis in a murine model of limb ischemia by recombinant periostin and its fasciclin I domain. Biochim Biophys Acta. 2014;1842(9):1324-32.

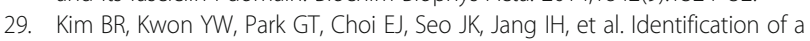
novel angiogenic peptide from periostin. PLoS One. 2017;12(11):e0187464.

30. Kwon YW, Heo SC, Lee TW, Park GT, Yoon JW, Jang IH, et al. N-acetylated prolineglycine-proline accelerates cutaneous wound healing and neovascularization by human endothelial progenitor cells. Sci Rep. 2017;7:43057.

31. Nayerossadat N, Maedeh T, Ali PA. Viral and nonviral delivery systems for gene delivery. Adv Biomed Res. 2012;1:27.
32. Long J, Kim H, Kim D, Lee JB, Kim DH. A biomaterial approach to cell reprogramming and differentiation. J Mater Chem B. 2017;5(13):2375-9.

33. Baek S, Oh J, Song J, Choi H, Yoo J, Park GY, et al. Generation of integrationfree induced neurons using graphene oxide-Polyethylenimine. Small (Weinheim an der Bergstrasse, Germany). 2017;13(5).

34. Benton G, Arnaoutova I, George J, Kleinman HK, Koblinski J. Matrigel: from discovery and ECM mimicry to assays and models for cancer research. Adv Drug Deliv Rev. 2014;79-80:3-18.

35. Evans ND, Gentleman E, Polak JM. Scaffolds for stem cells. Mater Today. 2006;9(12):26-33.

36. Hinderer S, Layland SL, Schenke-Layland K. ECM and ECM-like materials biomaterials for applications in regenerative medicine and cancer therapy. Adv Drug Deliv Rev. 2016;97:260-9.

37. Rice JJ, Martino MM, De Laporte L, Tortelli F, Briquez PS, Hubbell JA. Engineering the regenerative microenvironment with biomaterials. Adv Healthc Mater. 2013;2(1):57-71.

38. Dash BC, Xu Z, Lin L, Koo A, Ndon S, Berthiaume F, et al. Stem cells and engineered scaffolds for regenerative wound healing. Bioengineering (Basel). 2018;5(1).

39. Kook YJ, Lee DH, Song JE, Tripathy N, Jeon YS, Jeon HY, et al. Osteogenesis evaluation of duck's feet-derived collagen/hydroxyapatite sponges immersed in dexamethasone. Biomater Res. 2017;21:2.

40. Ewa-Choy YW, Pingguan-Murphy B, Abdul-Ghani NA, Jahendran J, Chua KH. Effect of alginate concentration on chondrogenesis of co-cultured human adipose-derived stem cells and nasal chondrocytes: a biological study. Biomater Res. 2017;21:19.

41. Yao S, Liu X, Wang X, Merolli A, Chen X, Cui F. Directing neural stem cell fate with biomaterial parameters for injured brain regeneration. Progress in Natural Science: Materials International. 2013;23(2):103-12.

42. Zhang Z, Gupte MJ, Ma PX. Biomaterials and stem cells for tissue engineering. Expert Opin Biol Ther. 2013;13(4):527-40.

43. Ma H, Hu J, Ma PX. Polymer scaffolds for small-diameter vascular tissue engineering. Adv Funct Mater. 2010;20(17):2833-41.

44. Faulkner-Jones A, Fyfe C, Cornelissen DJ, Gardner J, King J, Courtney A, et al. Bioprinting of human pluripotent stem cells and their directed differentiation into hepatocyte-like cells for the generation of mini-livers in 3D. Biofabrication. 2015;7(4):044102.

45. Mandrycky C, Wang Z, Kim K, Kim D-H. 3D bioprinting for engineering complex tissues. Biotechnol Adv. 2016;34(4):422-34.

46. Cui $X$, Dean D, Ruggeri ZM, Boland T. Cell damage evaluation of thermal inkjet printed Chinese hamster ovary cells. Biotechnol Bioeng. 2010;106(6): 963-9.

47. Barron JA, Wu P, Ladouceur HD, Ringeisen BR. Biological laser printing: a novel technique for creating heterogeneous 3-dimensional cell patterns. Biomed Microdevices. 2004;6(2):139-47.

48. Murphy SV, Atala A. 3D bioprinting of tissues and organs. Nat Biotechnol. 2014:32(8):773-85.

49. Hennink WE, van Nostrum CF. Novel crosslinking methods to design hydrogels. Adv Drug Deliv Rev. 2002;54(1):13-36.

50. Mattimore JP, Groff RE, Burg T, Pepper ME, editors. A general purpose driver board for the HP26 ink-jet cartridge with applications to bioprinting. Proceedings of the IEEE SoutheastCon 2010 (SoutheastCon); 2010 18-21 March 2010.

51. Cui X, Boland T, D'Lima DD, Lotz MK. Thermal inkjet printing in tissue engineering and regenerative medicine. Recent patents on drug delivery \& formulation. 2012;6(2):149-55.

52. Li J, Chen M, Fan X, Zhou H. Recent advances in bioprinting techniques: approaches, applications and future prospects. J Transl Med. 2016;14:271.

53. Huang Y, Zhang XF, Gao G, Yonezawa T, Cui X. 3D bioprinting and the current applications in tissue engineering. Biotechnol J. 2017;12(8).

54. Seol YJ, Kang HW, Lee SJ, Atala A, Yoo JJ. Bioprinting technology and its applications. European journal of cardio-thoracic surgery : official journal of the European Association for Cardio-thoracic Surgery. 2014; 46(3):342-8.

55. Koch L, Gruene M, Unger C, Chichkov B. Laser assisted cell printing. Curr Pharm Biotechnol. 2013;14(1):91-7.

56. Gopinathan J, Noh I. Recent trends in bioinks for 3D printing. Biomater Res. 2018;22:11.

57. Zorlutuna P, Vrana NE, Khademhosseini A. The expanding world of tissue engineering: the building blocks and new applications of tissue engineered constructs. IEEE Rev Biomed Eng. 2013;6:47-62. 
58. Williams DF. On the mechanisms of biocompatibility. Biomaterials. 2008 , 29(20):2941-53.

59. Chen CC, Yu J, Ng HY, Lee AK, Chen CC, Chen YS, et al. The physicochemical properties of Decellularized extracellular matrix-coated 3D printed poly(epsilon-caprolactone) nerve conduits for promoting Schwann cells proliferation and differentiation. Materials (Basel). 2018;11(9).

60. Dolati F, Yu Y, Zhang Y, De Jesus AM, Sander EA, Ozbolat IT. In vitro evaluation of carbon-nanotube-reinforced bioprintable vascular conduits. Nanotechnology. 2014;25(14):145101.

61. Richards D, Jia J, Yost M, Markwald R, Mei Y. 3D Bioprinting for vascularized tissue fabrication. Ann Biomed Eng. 2017;45(1):132-47.

62. Jeon J, Lee MS, Yang HS. Differentiated osteoblasts derived decellularized extracellular matrix to promote osteogenic differentiation. Biomater Res. 2018;22:4

63. Melchiorri AJ, Hibino N, Best CA, Yi T, Lee YU, Kraynak CA, et al. 3D-printed biodegradable polymeric vascular grafts. Adv Healthc Mater. 2016;5(3):319-25

64. Weiss P, Obadia L, Magne D, Bourges X, Rau C, Weitkamp T, et al. Synchrotron $X$-ray microtomography (on a micron scale) provides threedimensional imaging representation of bone ingrowth in calcium phosphate biomaterials. Biomaterials. 2003;24(25):4591-601.

65. Inzana JA, Olvera D, Fuller SM, Kelly JP, Graeve OA, Schwarz EM, et al. 3D printing of composite calcium phosphate and collagen scaffolds for bone regeneration. Biomaterials. 2014;35(13):4026-34.

66. Teixeira BN, Aprile P, Mendonca RH, Kelly DJ, Thire R. Evaluation of bone marrow stem cell response to PLA scaffolds manufactured by 3D printing and coated with polydopamine and type I collagen. J Biomed Mater Res B Appl Biomater. 2018.

67. Markstedt K, Mantas A, Tournier I, Martinez Avila H, Hagg D, Gatenholm P. 3D Bioprinting human chondrocytes with Nanocellulose-alginate bioink for cartilage tissue engineering applications. Biomacromolecules. 2015;16(5): 1489-96.

68. Jariwala SH, Lewis GS, Bushman ZJ, Adair JH, Donahue HJ. 3D Printing of Personalized Artificial Bone Scaffolds. 3D Print Addit Manuf. 2015;2(2):56-64.

69. Lee SH, Jeong SK, Ahn SK. An update of the defensive barrier function of skin. Yonsei Med J. 2006;47(3):293-306.

70. Yoshikawa T, Mitsuno H, Nonaka I, Sen Y, Kawanishi K, Inada Y, et al. Wound therapy by marrow mesenchymal cell transplantation. Plast Reconstr Surg. 2008;121(3):860-77.

71. Kumbar SG, Nukavarapu SP, James R, Nair LS, Laurencin CT. Electrospun poly(lactic acid-co-glycolic acid) scaffolds for skin tissue engineering. Biomaterials. 2008;29(30):4100-7.

72. Ng WL, Wang S, Yeong WY, Skin Bioprinting NMW. Impending reality or fantasy? Trends Biotechnol. 2016;34(9):689-99.

73. Kim BS, Kwon YW, Kong JS, Park GT, Gao G, Han W, et al. 3D cell printing of in vitro stabilized skin model and in vivo pre-vascularized skin patch using tissue-specific extracellular matrix bioink: a step towards advanced skin tissue engineering. Biomaterials. 2018;168:38-53.

Ready to submit your research? Choose BMC and benefit from:

- fast, convenient online submission

- thorough peer review by experienced researchers in your field

- rapid publication on acceptance

- support for research data, including large and complex data types

- gold Open Access which fosters wider collaboration and increased citations

- maximum visibility for your research: over $100 \mathrm{M}$ website views per year

At $\mathrm{BMC}$, research is always in progress.

Learn more biomedcentral.com/submissions 